\title{
A IMPORTÂNCIA DAS UNIDADES DE CONSERVAÇÃO DO ARQUIPÉLAGO DE FERNANDO DE NORONHA
}

\author{
R. C. B. SANTANA* , H. P. SILVA, R. M. C. M. O. CARVALHO, M. N. M. A. FRUTUOSO e S. S. F. BRANDÃO \\ Instituto Federal de Educação, Ciência e Tecnologia de Pernambuco \\ rebysantana@hotmail.com*
}

Artigo submetido em março/2016 e aceito em setembro/2016

DOI: $10.15628 /$ holos.2016.4217

\section{RESUMO}

A constatação de que a sobrevivência humana depende da conservação do meio ambiente fez surgir a consciência de que era preciso preservá-lo. Uma das ferramentas utilizadas para atingir este objetivo foi a instituição do Sistema Nacional de Unidades de Conservação. O Arquipélago de Fernando de Noronha possui beleza paisagística singular e uma variedade de formas de vida marinha e terrestre, que justifica a existência de duas Unidades de Conservação em seu território: a Área de
Proteção Ambiental (APA) de Fernando de Noronha e o Parque Nacional Marinho (PARNAMAR) de Fernando de Noronha. Restringindo o acesso, orientando a ocupação e o uso dos recursos naturais, as Unidades de Conservação existentes em Fernando de Noronha tem contribuído para garantir a conservação do meio ambiente naquele território para as presentes e futuras gerações.

PALAVRAS-CHAVE: Meio Ambiente, SNUC, APA, PARNAMAR, Preservação.

\section{THE IMPORTANCE OF THE ARCHIPELAGO OF CONSERVATION UNITS OF FERNANDO DE NORONHA}

\begin{abstract}
The finding that human survival depends on conservation of the environment has given rise the awareness of need was to preserve it. Of the tools used to achieve this goal was the establishment of the National System of Conservation Units. The archipelago of Fernando de Noronha has natural scenic beauty and a variety of forms of marine and terrestrial life, which justifies the existence of two protected areas in its territory: the Environmental
\end{abstract}

Protection Area (APA) and Fernando de Noronha National Marine Park (PARNAMAR) Fernando de Noronha. Restricting access by directing the occupation and use of natural resources, conservation units existing in Fernando de Noronha has contributed to guarantee the conservation of the environment in that area for present and future generations.

KEYWORDS: Environment, SNUG, APA PARNAMAR, preservation. 


\section{INTRODUÇÃO}

Nas últimas décadas os debates acerca do tema "meio ambiente" têm sido aprofundados nas mais diversas instâncias da sociedade, sendo possível identificar na esfera pública, na comunidade acadêmica e na própria sociedade civil, como defende Carvalho (2011), uma crescente consciência de que da proteção e conservação dos sistemas naturais depende o futuro da humanidade.

As reflexões sobre o assunto, no entanto, devem iniciar com a própria compreensão do termo "meio ambiente", já que este, devido à sua complexidade poderá admitir diversas vertentes dependendo do prisma sob o qual é analisado. Este entendimento é o ponto de partida para as tomadas de decisão que irão nortear as ações de governança a serem adotadas para garantir a vida das futuras gerações.

Neste diapasão, Reigota, em 1991, criou uma tipologia, na qual classifica a percepção de meio ambiente em três categorias: a naturalista, onde o meio ambiente é sinônimo de natureza intocada, limitando-se aos elementos naturais; a antropocêntrica, cujo meio ambiente é compreendido como fonte de recursos naturais necessários para a sobrevivência humana; enquanto que na globalizante ocorre a interrelação entre homem e natureza no meio ambiente (PEIXOTO et.al., 2013).

Leite e Ayala (2000), todavia, propõem que o tema seja abordado de forma holística, ou seja, afastando-se da fragmentariedade e partindo de sua integridade. Defende, portanto, que o meio ambiente deriva do homem, estando a ele relacionado de tal forma que se apresentam na natureza como dois elos do mesmo feixe ou dois lados da mesma fruta.

Embora coexistam na atualidade conceitos de meio ambiente atrelados às diversas correntes apresentadas, os que consideram o homem como parte deste e responsável por respeitar os limites apresentados pelos ecossistemas existentes têm ganhado força e se estabelecido no seio da sociedade nos últimos anos.

A própria interpretação dada a definição legal de meio ambiente tem sido modificada ao longo do tempo para se adaptar às novas exigências da sociedade. A primeira delas é apresentada no Art. 3ㅇ, I da Lei no 6.938/81, Lei de Política Nacional do Meio Ambiente, que coloca: "Para fins previstos nesta lei, entende-se por: I-meio ambiente, o conjunto de condições, leis, influências e interações de ordem física, química e biológica, que permite, abriga e rege a vida em todas as suas formas".

Verifica-se que o conceito apresentado pela Lei 6.938/81 se aproxima da visão naturalista de meio ambiente, pois, como assegura Sirvinskas (2003), é restrito e demonstra apenas o conceito de meio ambiente natural, uma vez que não tutela outros bens jurídicos protegidos.

Com o advento da Constituição Federal de 1988, o direito a um meio ambiente ecologicamente equilibrado foi pela primeira vez previsto na Carta Magna brasileira, estabelecendo no art. 225 "todos tem direito ao meio ambiente ecologicamente equilibrado, bem de uso comum do povo e essencial à sadia qualidade de vida, impondo-se ao Poder Público e à coletividade o dever de defendê-lo e preservá-lo para as presentes e futuras gerações. " 
Limitando-se neste primeiro momento a analisar simplesmente a amplitude do termo meio ambiente utilizado na Constituição Federal é possível afirmar que este foi estendido, passando a colocá-lo como condição sine qua non para a existência de uma vida saudável e de qualidade. Nos dizeres de Fiorillo (2004), a noção de meio ambiente é ampla, tendo o legislador optado por trazer um conceito jurídico indeterminado, a fim de criar um espaço amplo de incidência da norma, aproximando-se, portanto, de uma corrente globalizante.

Diante do apresentado optou-se, no âmbito deste artigo, pela utilização do conceito de meio ambiente apresentado por Silva (2003, p. 20), que o define como "a interação do conjunto de elementos naturais, artificiais e culturais que propiciem o desenvolvimento equilibrado da vida em todas as suas formas", por considerar este o homem como um dos elementos que compõem o ambiente em que vive e do qual extraem os recursos que garantem sua sobrevivência.

O meio ambiente, nas suas diversas concepções, alcançou o patamar de tema de interesse global onde as "pequenas" mudanças a nível local vão interferir na qualidade de vida de todos os habitantes da Terra.

Não é gratuita, portanto, a preocupação com a proteção de áreas específicas que possuam ecossistemas de características singulares. Instituindo-se para tal fim, no âmbito brasileiro, o Sistema Nacional de Unidades de Conservação composto por diferentes categorias, de acordo com a finalidade específica a ser alcançada.

Neste diapasão o Arquipélago de Fernando de Noronha, dono de beleza paisagística única e possuidor de um meio ambiente propício para a reprodução de diversas espécies da fauna e flora marinha e terrestre, foi agraciado com a criação de duas Unidades de Conservação em seu território. Sendo uma de Uso Sustentável, a Área de Proteção Ambiental de Fernando de Noronha, e outra de Proteção Integral, o Parque Nacional Marinho de Fernando de Noronha, atingindo assim a totalidade de proteção ambiental em sua área.

O presente estudo tem, portanto, como objetivo analisar a função das Unidades de Conservação, enquanto entidades agentes de governança pública, para a proteção do meio ambiente no Arquipélago de Fernando de Noronha, optando-se pela realização de uma pesquisa bibliográfica e documental, em livros, artigos científicos e documentos disponíveis em meio físico e digital.

\section{ARQUIPÉLAGO DE FERNANDO DE NORONHA}

Localizado no Oceano Atlântico, distante $345 \mathrm{Km}$ do Cabo de São Roque-Rio Grande do Norte, ponto mais próximo da costa brasileira, $545 \mathrm{~km}$ do litoral do Estado de Pernambuco, responsável pela administração, e a aproximadamente $2.700 \mathrm{~km}$ do litoral africano (TEIXEIRA et al, 2003).

O Arquipélago de Fernando de Noronha supõe-se haver sido descoberto pelo navegador Américo Vespúcio, no ano de 1503, durante a realização da 1a Expedição Exploratória, que partira de Lisboa, Portugal, com o objetivo de descobrir Málaga, sob o Comando de Gaspar de Lemos e financiada pelo nobre português Fernão de Loronha, a quem o arquipélago foi cedido na forma de capitania hereditária e posteriormente recebeu seu nome (SILVA, 2013). 
Desde então, o conjunto de ilhas (Fernando de Noronha, Rata, Rasa, Do Meio e Lucena), rochedos e lajedos, ressalta a mesma autora, vêm sendo reconhecido por sua pura beleza paisagística. Chegando a ser considerada, em 2001, Sítio do Patrimônio Mundial Natural pela Organização das Nações Unidas para a Educação, a Ciência e a Cultura (UNESCO).

A beleza paisagística, evidenciada na Figura 1, não é a única relíquia encontrada no arquipélago. Pois, a diversidade de formas de vida ali existente interage de maneira singular, para formar um verdadeiro paraíso sob a face da Terra.

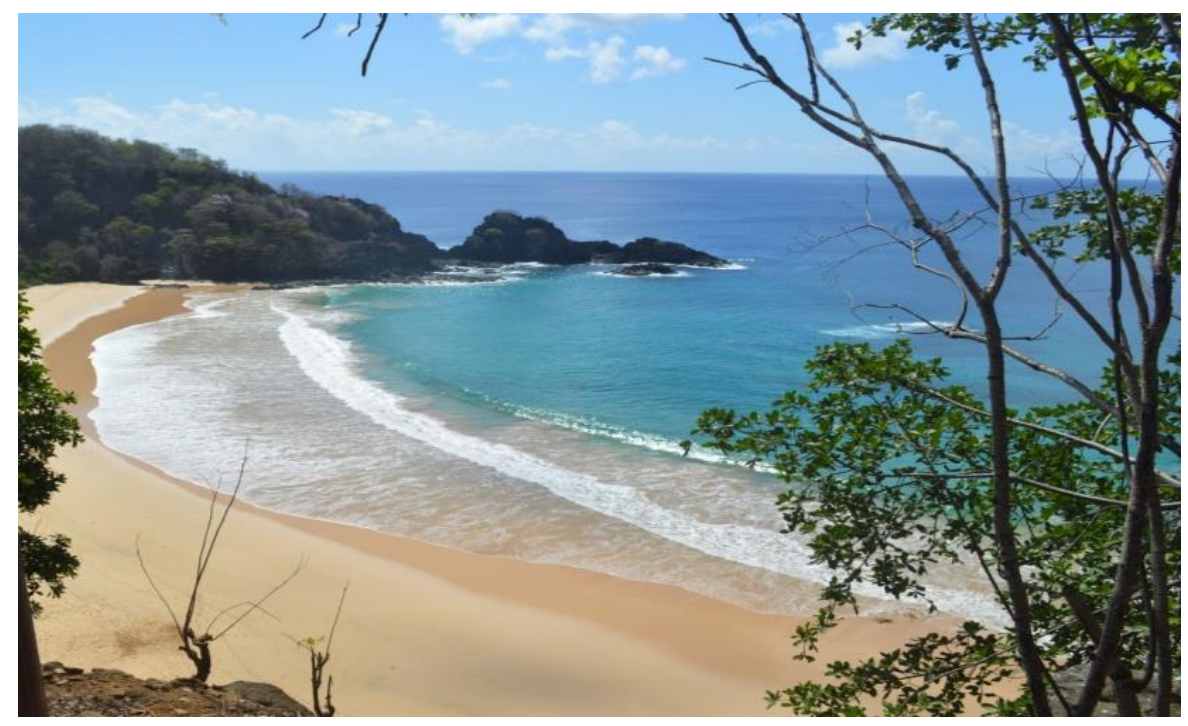

Figura 1: Vista da Praia do Sancho, Fernando de Noronha-PE. Fonte: os autores

Em Fernando de Noronha encontram-se os últimos vestígios de Mata Atlântica insular e o único manguezal oceânico do Atlântico Sul, configurando-se como área de extrema importância biológica para a conservação da Zona Marinha. Constitui-se, portanto, em um grande banco de alimentação e reprodução para toda a fauna marinha do Nordeste brasileiro (ANDRADE et al, 2009).

A construção deste meio ambiente tão propício para a multiplicação de espécies variadas é realizada a partir da interação de fatores endêmicos e antrópicos que se sedimentaram ao longo dos anos.

De origem vulcânica, o Arquipélago corresponde aos cimos de uma montanha submarina que se ergue a partir do assoalho oceânico, situado a uma profundidade de $4.000 \mathrm{~m}$. A base da elevação submarina tem uma circunferência com perto de $200 \mathrm{~km}$, adquirindo nítida orientação EW a partir de $2.500 \mathrm{~m}$ de profundidade (MMA, 2004). O que torna possível afirmar que embora aparentem independência na superfície, as ilhas, ilhotas e rochedos que compõem o Arquipélago de Fernando de Noronha são originadas da mesma formação vulcânica, que hoje se encontra submersa.

Basicamente, as rochas de origem vulcânica agrupam-se em três formações geológicas distintas, que consistem nas Formações Remédios, Quixaba e São José. Sendo todas elas de natureza altamente sódico-alcalina, sub-saturadas em sílica, cujos teores variam de $34,4 \%$ nos melilitaankaratritos, a $60,8 \%$ nos álcali-traquitos. A litoquímica apresentada confere ao vulcanismo 
características que colocam o Arquipélago de Fernando de Noronha entre as ilhas oceânicas mais alcalinas do Planeta (MMA, 2004).

A precipitação média anual de chuvas é de $1.300 \mathrm{~mm}$, concentrada essencialmente na estação úmida que vai de março a maio. Possuindo uma pequena variabilidade de temperatura no transcorrer do ano, com uma média situando-se em torno de $25^{\circ} \mathrm{C}$ (OLIVEIRA et al, 2011).

A característica apresentada acima vai influenciar diretamente num dos principais problemas enfrentados em Noronha, o abastecimento de água. Este tem sido empreendido, desde os tempos iniciais da ocupação humana, através da captação de água de chuva nos açudes existentes, que estão sujeitos a assoreamento e têm chegado a transbordar em períodos de chuva mais intensa, devido à redução da capacidade de acúmulo de água, em função do aumento da carga de sólidos (BATISTELLA, 1993).

Outro fator que vai influenciar o meio ambiente é a ação das correntes marinha, onde a região do Arquipélago de Fernando de Noronha sofre a ação da Corrente Sul Equatorial que exerce influência na distribuição das isotermas dessa massa d'água, com a indução de ressurgências que atingem a camada eufótica nas áreas dos bancos mais profundos (TRAVASSO, 1999).

Todavia, o fator que mais vai interferir na composição do meio ambiente é a ocupação humana, que foi realizada de forma gradativa desde o seu descobrimento. Várias foram as fases pelas quais passaram, desde a invasão francesa, até a utilização como presídio político.

Sendo Fernando de Noronha considerado Território Federal por meio do Decreto-Lei no 4.102, de 9 de fevereiro de 1942 e vinculado ao Ministério do Interior, para efeitos de supervisão ministerial, pelo Decreto nำ4.780, de 14 de agosto de 1987.

O Território Federal de Fernando de Noronha, todavia, foi extinto pelo artigo 15 dos Atos das Disposições Constitucionais Transitórias da Constituição Federal (ADCT), "Fica extinto o Território Federal de Fernando de Noronha, sendo sua área reincorporada ao Estado de Pernambuco", ficando sob a responsabilidade deste Estado a execução de políticas públicas de natureza social e econômica, inclusive no que diz respeito à gestão urbanística do uso do solo, compatibilizada com as normas constitucionais e infraconstitucionais de proteção ao meio ambiente.

O novo status administrativo impulsionou transformações fundamentais na forma de ocupação e no uso dos atributos naturais, mudanças iniciadas na década de 1980, quando essa distante e preciosa porção oceânica começou a ser visitada, ainda de forma tímida e precária, por turistas (TADA et al, 2010).

A população residente também teve um incremento em seu número aumentando de 1686, em 1991, para 2630, em 2010, conforme disposto na Tabela 1. Cabendo ressaltar que este é o número de residentes fixos, não sendo considerada a população flutuante, ou seja, visitantes. Tal aumento vai interferir na qualidade dos serviços públicos da ilha, bem como na própria capacidade do meio ambiente de suportar o aumento populacional. 
Tabela 1: Evolução Populacional.

\begin{tabular}{c|c}
\hline Ano & Número de Habitantes \\
\hline 1991 & 1686 \\
\hline 1996 & 1522 \\
\hline 2000 & 2051 \\
\hline 2007 & 2801 \\
\hline 2010 & 2630 \\
\hline
\end{tabular}

Fonte: IBGE (1991, 1996, 2000, 2007 e 2010)

Apesar de não haver uma população tradicional em Fernando de Noronha, nos termos previstos na Lei do Sistema de Unidades de Conservação, ou seja, no sentido de população isolada com pouca interferência externa, é possível identificar nos residentes permanentes a figura do "ilhéu", que tem suas características próprias bastante enraizadas, se contrapondo à identidade daqueles vindos recentemente do continente (MMA, 2004).

O aumento da população tem preocupado os especialistas, pois de acordo como IBGE (2010) a densidade demográfica do Arquipélago, considerando todos os $17 \mathrm{Km}^{2}$ da llha principal é de $154,55 \mathrm{hab} / \mathrm{km}^{2}$. Já o Plano de Manejo aponta que a densidade demográfica da Ilha dentro dos limites da APA de $8 \mathrm{~km}^{2}$ é de $290,1 \mathrm{hab} / \mathrm{km}^{2}$, salientando que se considerada somente as zonas permitidas para residência e visitação dentro da Área de Preservação Ambiental, este número aproxima-se de $1.000 \mathrm{hab} / \mathrm{km}^{2}$. Tal aumento populacional tornou-se, então, um dos pontos críticos no que se refere ao equilíbrio ambiental existente na Ilha, sendo assim, para que se evite um colapso no futuro, a população da Ilha deve limitar-se aos números atuais, conforme já apontava o Estudo da Capacidade de Suporte da Ilha desenvolvido em 2007.

O Arquipélago de Fernando de Noronha caracteriza-se, portanto, por ser um território de singular beleza e importância ambiental mundialmente reconhecida e que necessita de ações conjuntas de governança no sentido de protegê-la para que as futuras gerações possam usufruir de seus atrativos.

\section{SISTEMA NACIONAL DE UNIDADES DE CONSERVAÇÃO}

A crise ambiental, ou seja, a constatação de que a degradação ambiental atingiu níveis que passavam a arriscar a própria sobrevivência humana, fez, como citado anteriormente, com que surgisse uma consciência social de que era necessário preservar o meio ambiente e parar de utilizar a natureza como fonte inesgotável de recursos (LIMA et al, 2011).

No Brasil, esta consciência se refletiu no arcabouço jurídico da nação, chegando ao seu ápice na previsão constitucional do Direito a um Meio Ambiente ecologicamente equilibrado, indo além ao impor como obrigação a ser partilhada entre o poder público e a sociedade civil o dever de defendê-lo e preservá-lo de modo que as futuras gerações possam usufruir de tal bem.

Ante a necessidade de estabelecer meios capazes de garantir a efetividade de tal direito foi instituído, entre outras ferramentas, o Sistema Nacional de Unidades de Conservação por meio da Lei no 9.985, de 18 de julho de 2000, que de acordo com seu Art. 10 "estabelece critérios e normas para a criação, implantação e gestão das unidades de conservação". 
A utilização da delimitação de áreas com restrição de acesso e retirada dos bens naturais existentes no território protegido pela Unidade de Conservação como forma de preservação de árvores, florestas, animais e meio ambiente, não é exclusividade brasileira, nem esta é a primeira tentativa nacional de fazê-la.

Relata Hassler (2005), que já na época medieval se manifestava este tipo de preocupação, externada por meio de Leis Florestais que restringiam o acesso as reservas de caça reais. Era a Floresta de Bialowiesa, na Polônia, considerada a mais antiga reserva de fauna do mundo, já que se encontra sob proteção desde o século XIV por determinação do rei Jagellon.

O mesmo autor ressalta ainda que a criação do Parque Nacional de Yellowstone, nos Estados Unidos, em 1872, inaugurou uma nova fase nos procedimentos para preservação do meio ambiente, uma vez que o Estado passou a assumir oficialmente o gerenciamento de tais áreas. Constituiu-se, portanto, numa das principais formas de intervenção governamental para reduzir a degradação ambiental.

A primeira vez que o Brasil efetuou um planejamento do sistema de unidades de conservação para o país foi nos anos 1970, por meio do "Plano do Sistema de Unidades de Conservação do Brasil", tendo sido aprovado pelo governo e publicado oficialmente em 1979. Na ocasião, o país possuía dezoito Parques Nacionais e oito Reservas Biológicas, em face de existência de leis que indicavam várias áreas para o estabelecimento de novas unidades de conservação, em especial na região da Amazônia, na Caatinga e na região costeiro-marinha, como, por exemplo, o Código Florestal (1965) e a Lei de Proteção à Fauna (1967) (PÁDUA, 2011).

Os debates entre ambientalistas seguiram, pois se verificou a necessidade de uma legislação mais consistente. Neste contexto, a instituição do Sistema Nacional de Unidades de Conservação, por meio da Lei no 9.985/00, representou um avanço nas diretrizes e procedimentos para criação, implantação e gestão de unidades de conservação das três esferas de governo (federal, estadual e municipal).

Nos termos estabelecidos no Art. 2ํ, I, da lei supracitada, Unidade de Conservação refere-se ao:

Espaço territorial e seus recursos ambientais, incluindo as águas jurisdicionais, com características naturais relevantes, legalmente instituído pelo Poder Público, com objetivos de conservação e limites definidos, sob regime especial de administração, ao qual se aplicam garantias adequadas de proteção.

Sendo assim, busca-se proteger os recursos naturais existentes em áreas limitadas, que devido às suas características necessitem de uma tutela especial por parte dos entes estatais. Podendo a Unidade de Conservação ser instituídas nas três esferas de governo.

As peculiaridades de cada região, bioma, comunidade e ambiente não devem ser descartadas por ocasião da criação de uma Unidade de Conservação. Por tal motivo, o legislador optou por dividir em duas categorias as Unidades de Conservação integrantes do Sistema Nacional de Unidades de Conservação com características específicas, quais sejam: Unidades de Proteção Integral e Unidades de Uso Sustentável. 
Cada grupo deste vai ser composto por espécies de Unidades de Conservação, sendo que "cada espécie de unidade de conservação ou espaço protegido tem finalidade própria criada pela lei, dependendo dos atributos que justifiquem a sua proteção" (HASSLER, 2005, p. 85).

Encontram-se dispostas na Tabela 2 as duas categorias de Unidades de Conservação, com os seus respectivos objetivos e espécies componentes, a fim de que se torne mais acessível a compreensão da disposição prevista na legislação que trata do tema.

Tabela 2: Espécies de Unidades de Conservação por Categoria.

\begin{tabular}{|c|c|c|}
\hline Categoria & Objetivo & Denominação \\
\hline \multirow{5}{*}{ Proteção Integral } & \multirow{5}{*}{$\begin{array}{l}\text { Preservação da natureza, sendo admitido } \\
\text { apenas o uso indireto de seus recursos } \\
\text { naturais. }\end{array}$} & Estação Ecológica \\
\hline & & Reserva Biológica \\
\hline & & Parque Nacional \\
\hline & & Monumento Natural \\
\hline & & Refúgio de Vida Silvestre \\
\hline \multirow{7}{*}{ Uso Sustentável } & \multirow{7}{*}{$\begin{array}{l}\text { Compatibilização entre a conservação da } \\
\text { natureza com o uso sustentável de parcela } \\
\text { de seus recursos naturais }\end{array}$} & Área de Proteção Ambiental-APA \\
\hline & & Área de Relevante Interesse Ecológico-ARIE \\
\hline & & Floresta Nacional-FLONA \\
\hline & & Reserva Extrativista \\
\hline & & Reserva de Fauna \\
\hline & & Reserva de Desenvolvimento Sustentável-RDS \\
\hline & & Reserva Particular do Patrimônio Natural-RPPN \\
\hline
\end{tabular}

Fonte: ANTUNES, 2011, p. 241.

Nas espécies que integram a categoria de Unidades de Proteção Integral, não se admite consumo, coleta, dano ou destruição dos recursos naturais. A interferência humana deve ser evitada, no intuito de que o ecossistema do referido grupo fique livre de alterações decorrentes da ação do homem (GARBELINI, 2011).

As Unidades de Conservação de Proteção Integral estão previstos no Art. 8o da Lei $\mathrm{n}$ ㅇ 9.985/00, que são: Estação Ecológica, Reserva Biológica, Parque Nacional, Monumento Natural e Refúgio de Vida Silvestre. O objetivo de cada uma delas passa a ser definido e detalhado a seguir, em conformidade com o que consta nos artigos de nove a treze da supracitada lei.

A Estação Ecológica é a primeira Unidade de Conservação apresentada pela lei, tendo como objetivo precípuo a preservação da natureza e a realização de pesquisas científicas. Devendo a área delimitada ser de posse e domínio públicos e realizada a desapropriação das áreas particulares incluídas em seus limites (Brasil, 2000).

O objetivo maior da Reserva Biológica é a preservação integral da biota e demais atributos naturais existentes em seus limites, não sendo permitida a interferência direta do homem ou modificações em seu ambiente. Exclui-se deste contexto as medidas de recuperação de seus ecossistemas alterados e as ações de manejo necessárias para recuperar e preservar o equilíbrio natural, a diversidade biológica e os processos ecológicos naturais. Rylands e Brandon (2005) ressaltam que também estão excluídas das limitações do uso humano as ações voltadas à educação ambiental.

O Parque Nacional tem como finalidade básica a preservação de ecossistemas naturais de grande relevância ecológica e beleza cênica, de modo a possibilitar a realização de pesquisas científicas e o desenvolvimento de atividades de educação e interpretação ambiental, de recreação 
em contato com a natureza e de turismo ecológico, constitui-se, assim, em área de posse e domínio públicos (MILARÉ, 2007).

O objetivo precípuo do Monumento Natural é, basicamente, a preservação de sítios naturais raros, singulares ou de grande beleza cênica. Pode ser constituído de áreas particulares, desde que exista a compatibilização entre os objetivos da unidade com a utilização da terra e dos recursos naturais do local pelos proprietários (BRASIL, 2000).

A última Unidade de Conservação prevista como sendo de proteção integral é o Refúgio de Vida Silvestre, que tem como meta proteger ambientes naturais onde se asseguram condições para a existência ou reprodução de espécies ou comunidades de flora local e da fauna residente ou migratória. Do mesmo modo como ocorre com o Monumento Natural, o Refúgio de Vida Silvestre também pode ser constituído de áreas particulares, ante a compatibilização entre os objetivos da unidade com a utilização da terra e dos recursos naturais do local pelos proprietários (SCHENINI; COSTA; CASARIN, 2004).

As Unidades de Conservação denominadas Monumento Natural e Refúgio de Vida Silvestre deveriam ser classificadas como de uso sustentável, em virtude de haver previsão legal de utilização de recursos naturais por parte dos proprietários de tais áreas particulares (MILARÉ, 2007).

De acordo com o Art. 70, §2ำ, da Lei no 9.985/00, o objetivo das Unidades de Uso Sustentável é compatibilizar a conservação da natureza com o uso sustentável de parcela dos seus recursos naturais. Os tipos passam a ser detalhados a partir do Art. 14, compondo este grupo estão: Área de Proteção Ambiental, Área de Relevante Interesse Ecológico, Floresta Nacional, Reserva Extrativista, Reserva de Fauna, Reserva de Desenvolvimento Sustentável, e Reserva Particular do Patrimônio Natural.

A Área de Proteção Ambiental tem como objetivo proteger a diversidade biológica, disciplinar o processo de ocupação e assegurar a sustentabilidade do uso dos recursos naturais, de forma a proporcionar a qualidade ambiental para as comunidades locais por meio de planos de manejo e zoneamento. Este se constitui um dos mecanismos que tem sido amplamente adotado no Brasil especialmente como zona tampão para parques e reservas (RYLANDS; BRANDON, 2005).

A Área de Relevante Interesse Ecológico é uma área em geral de pequena extensão, com pouca ou nenhuma ocupação humana, com características naturais extraordinárias ou que abriga exemplares raros da biota regional, e tem como objetivo manter os ecossistemas naturais de importância regional ou local e regular o uso admissível dessas áreas, de modo a compatibilizá-lo com os objetivos de conservação da natureza (BRASIL, 2000).

A Floresta Nacional é uma área com cobertura florestal de espécies nativas ou plantadas com o objetivo básico do uso múltiplo sustentável dos recursos florestais, com ênfase na geração de produtos e subprodutos florestais e a pesquisa científica. A visitação pública é permitida, no entanto, é condicionada às normas estabelecidas no plano de manejo pelo órgão responsável pela administração do local (MILARÉ, 2007).

Enquanto que a Reserva Extrativista se caracteriza por ser uma área utilizada por populações extrativistas tradicionais, tendo como objetivo principal proteger os meios de vida e a cultura dessas populações, e assegurar o uso sustentável dos recursos naturais da unidade. De acordo com Becker 
(2004), sua inclusão no Sistema Nacional de Unidades de Conservação é fruto da luta dos seringueiros por sua sobrevivência na floresta, contra a expansão dos fazendeiros de gado e os projetos de colonização do Instituto Nacional de Colonização e Reforma Agrária.

Já a Reserva de Fauna se constitui em uma área natural com populações animais de espécies nativas, terrestres ou aquáticas, residentes ou migratórias, adequadas para estudos técnicocientíficos sobre o manejo econômico sustentável de recursos faunísticos (MILARÉ, 2007).

A Reserva de Desenvolvimento Sustentável é uma área natural que abriga populações tradicionais, tendo como objetivo básico preservar a natureza e, ao mesmo tempo, assegurar as condições e os meios necessários para a reprodução e a melhoria dos modos e da qualidade de vida e exploração dos recursos naturais destas populações. De acordo com Medeiros (2006), juntamente com a reserva extrativista, esta Unidade representa um importante avanço na concepção de áreas protegidas no Brasil, pois incorpora concretamente aos objetivos da conservação as ações de inclusão social e econômica das populações diretamente afetadas.

A última Unidade de Conservação de Uso Sustentável é a Reserva Particular do Patrimônio Natural que se trata de uma área privada, gravada com perpetuidade, por vontade do proprietário, com o objetivo de conservar a biodiversidade, a beleza cênica ou contribuir para a preservação de ecossistemas frágeis ou ameaçados. Para Mendonça (2004), as Reservas Particulares do Patrimônio Natural representam um dos primeiros passos para envolver a sociedade civil na conservação da diversidade biológica e aumenta significativamente a possibilidade de se obter um cenário em que haverá muito mais áreas protegidas, tanto em termos de qualidade quanto de quantidade.

A obrigatoriedade de utilização do plano de manejo e os conselhos enquanto ferramentas de gestão constitui um avanço. O Plano de Manejo é responsável por zonear a unidade de conservação e dizer onde a visitação pública será permitida e estabelecer as regras a serem seguidas. Já os Conselhos vão garantir a participação popular na gestão das Unidades, sendo Consultivos para as Unidades de Conservação de Proteção Integral e Deliberativos para as de Uso Sustentável (PÁDUA, 2011).

Embora estas ferramentas estejam previstas na legislação, suas reais utilizações precisam ser ampliadas, no intuito de fortalecer a participação social na gestão das unidades de conservação, potencializando a conscientização quanto à necessidade de conservação do meio ambiente e a própria eficácia da unidade.

\section{UNIDADES DE CONSERVAÇÃO DE FERNANDO DE NORONHA}

A previsão na lei da possibilidade de criação de Unidades de Conservação para a proteção ambiental contribuiu para que fossem implantadas no Distrito Estadual de Fernando de Noronha duas Unidades de Conservação: o Parque Nacional Marinho de Fernando de Noronha (PARNAMARFN) e a Área de Preservação Ambiental de Fernando de Noronha (APA-FN), Figura 2, ambas exercendo importante função na preservação das características endêmicas das ilhas que compõem este patrimônio mundial. 
As características das Unidades de Conservação existentes em Noronha vão ser distintas, pois "cada espécie de unidade de conservação ou espaço protegido tem finalidade própria criada pela lei, dependendo dos atributos que justifiquem a sua proteção" (HASSLER, 2005, p. 85).

As belezas naturais e o estado de conservação ambiental do arquipélago são fatores de reconhecimento da importância em nível mundial do Arquipélago de Fernando de Noronha. Um estudo relacionado às Zonas Costeira e Marinha, realizado pelo Ministério do Meio Ambiente Secretaria de Biodiversidade e Floresta (2002) no âmbito do PROBIO, conhecido como "Avaliação e Ações Prioritárias para a Conservação da Biodiversidade das Zonas Costeira e Marinha", classificou o Arquipélago de Fernando de Noronha como área de extrema importância biológica para a conservação da Zona Marinha.

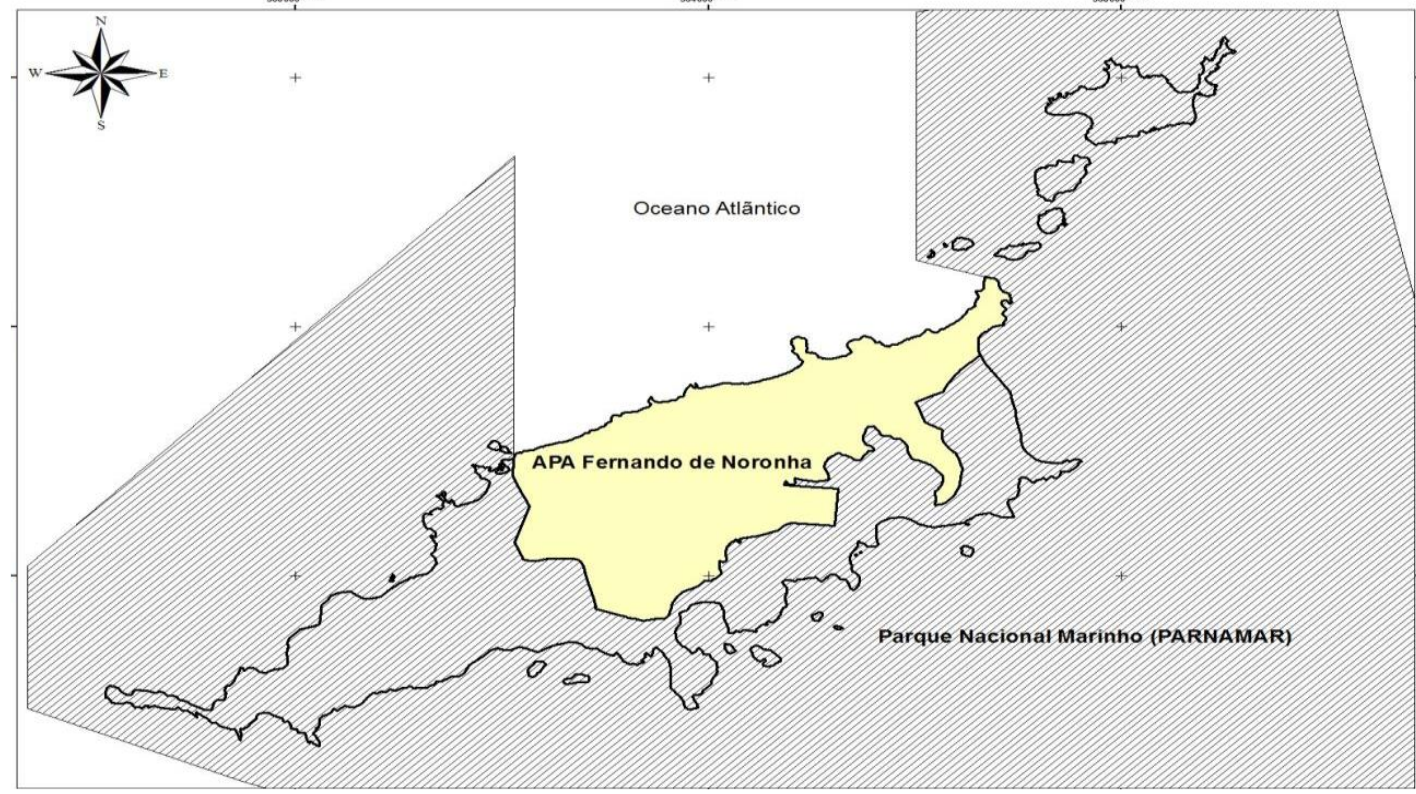

Figura 2: Limites das duas unidades de conservação homologadas por Lei Federal no Arquipélago Fernando de Noronha

Fonte: GEOSERE, adaptado SECTMA (2006)

O Instituto Chico Mendes de Conservação da Biodiversidade (ICMBio), autarquia em regime especial, criada pela Lei 11.516, de 28 de agosto de 2007, vinculada ao Ministério do Meio Ambiente e integrante do o Sistema Nacional do Meio Ambiente é órgão responsável pela gestão das Unidades de Conservação noronhense.

\subsection{Parque Nacional Marinho de Fernando de Noronha}

O Parque Nacional Marinho de Fernando de Noronha foi instituído por meio do Decreto no 96. 693, de 14 de setembro de 1988, com o objetivo de proteger amostras representativas dos ecossistemas marinhos e terrestres do arquipélago, bem como de assegurar a preservação de sua fauna, flora e demais recursos naturais, proporcionando oportunidades controladas para visitação, educação e pesquisa científica, no intuito de contribuir para a proteção de sítios e estruturas de interesse histórico-cultural que porventura possam existir na área. O referido parque está localizado entre as coordenadas geográficas: latitude $3^{\circ} 45^{\prime}$ e $3^{\circ} 56^{\prime} \mathrm{S}$ e longitude $32^{\circ} 20^{\prime}$ e $32^{\circ} 30^{\prime} \mathrm{W}$. 
A criação desta Unidade de Conservação foi estimulada por ambientalistas e pela comunidade local em virtude dos impactos ambientais que as mudanças na administração do Arquipélago, decorrentes da extinção do Território Federal, do Governo Federal para o Estado de Pernambuco poderiam acarretar. Levando, desta forma, a União a decretar a criação do Parque Nacional Marinho de Fernando de Noronha, que passou a abranger cerca de 70 \% do arquipélago, incluindo a totalidade das ilhas secundárias e, na porção marinha, um perímetro que envolve áreas com até 50 metros de profundidade (TADA et al, 2010). Desta feita, ficou a área referente aos $30 \%$ restantes da Ilha sob a égide de proteção da APA de Fernando de Noronha, por ser este um tipo de Unidade de Conservação que permite a ocupação humana para a realização do uso sustentável de parcela de seus recursos naturais.

Graças ao equilíbrio ecológico e a conscientização da população envolvida, o Parque Nacional Marinho constitui-se em habitat de variadas espécies animais terrestres e marinhos. No estudo desenvolvido por Machado (2008) foi possível identificar algumas espécies encontradas no Parque Nacional Marinho de Fernando de Noronha e que estão ameaçados de extinção, dentre as quais se destacam: tartaruga-cabeçuda, tartaruga-verde, tartaruga-de-pente, estrela-do-mar, tubarão-lixa, baleia-jubarte, caranguejo, pardela de asa-larga, entre outros.

O Plano de Manejo do Parque Nacional Marinho, finalizado em 1990, apresenta um zoneamento específico para a área do Parque, dividindo-a em: Zona Intangível, Zona Primitiva, Zona de Uso Extensivo, Zona de Uso Intensivo, Zona Histórico-Cultural, Zona de Recuperação e Zona de Uso Especial (FUNATURA/IBAMA, 1990).

O Conselho Consultivo do Parque Nacional de Fernando de Noronha foi criado por meio da Portaria do Instituto Brasileiro do Meio Ambiente e dos Recursos Naturais Renováveis no 190, de 31 de dezembro de 2001, com a finalidade de contribuir para com o planejamento de suas ações. Devendo, nos termos do Art. 2ㅇ da referida Portaria, ter a seguinte composição: Chefe do Parque Nacional Marinho de Fernando de Noronha, Chefe da Área de Proteção Ambiental de Fernando de Noronha, um representante da Gerência Executiva do IBAMA em Pernambuco, um representante da Administração do Distrito Estadual de Fernando de Noronha, um representante do Conselho Distrital de Fernando de Noronha, um representante da Secretaria de Ciência, Tecnologia e Meio Ambiente do Estado de Pernambuco, um representante do Destacamento de Aeronáutica de Fernando de Noronha do Segundo Comando Aéreo Regional, um representante da Associação Popular Noronhense, um representante do Centro Golfinho Rotador- Fernando de Noronha, um representante do WWF-Brasil, um representante da Fundação Pró-Tamar, três representantes das entidades representativas dos setores produtivos relacionados com as atividades de turismo ecológico em Fernando de Noronha. Reunindo assim, atores de governança pública e privada que estão diretamente ligados ao Parque.

\section{2 Área de Proteção Ambiental de Fernando de Noronha}

A Área de Proteção Ambiental de Fernando de Noronha - Rocas - São Pedro e São Paulo foi criada por meio do Decreto Federal no 92.755, de 05 de junho de 1986, abrangendo três áreas distintas, o Arquipélago de Fernando de Noronha, o Atol das Rocas e o Arquipélago de São Pedro e São Paulo, num total de 79.706 ha de área protegida. 
No território de Fernando de Noronha foi, inicialmente, delimitada pelas seguintes coordenadas latitude $03^{\circ} 45^{\prime} \mathrm{S}$ a $03^{\circ} 57^{\prime} \mathrm{S}$ e longitude $32^{\circ} 19^{\prime} \mathrm{W}$ a $32^{\circ} 41^{\prime} \mathrm{W}$. Esta área de proteção de uso sustentável da ilha veio a ser delimitada posteriormente pelo Decreto de criação do Parque Nacional Marinho de Fernando de Noronha no ano de 1988, ficando sob sua égide a porção territorial que não estivesse incluída na área do Parque.

O Plano de Manejo da Área de Proteção Ambiental prevê o zoneamento do território sob sua proteção, no intuito de cumprir o determinado na Lei $n$ - 9.985/00, que o conceitua, em seu artigo $2^{\circ}$, inciso $\mathrm{XVI}$, como:

Definição de setores ou zonas em uma unidade de conservação com objetivos de manejo e normas específicos, com o propósito de proporcionar os meios e as condições para que todos os objetivos da unidade possam ser alcançados de forma harmônica e eficaz.

Constituindo-se, portanto, em um instrumento de ordenamento territorial, estabelece usos diferenciados para cada zona, segundo seus objetivos, regulando, dentre outras coisas, o grau de intervenção antrópica, ou seja, de intervenção humana esperada em cada região. Identifica-se as seguintes zonas: Proteção da Vida Silvestre, Conservação, Recuperação, Histórico-Cultural, Agropecuária, Uso Especial, Urbana, Recreação Marinha, Exclusiva de Pesca Artesanal, Pesca.

O Conselho Deliberativo da Área de Proteção Ambiental de Fernando de Noronha foi instituído através da Portaria do Instituto Brasileiro do Meio Ambiente e dos Recursos Naturais Renováveis no 191, de 31 de dezembro de 2001, com a seguinte composição: Chefe da Área de Proteção Ambiental de Fernando de Noronha, Chefe do Parque Nacional Marinho de Fernando de Noronha, um representante da Gerência Executiva do IBAMA em Pernambuco, um representante da Administração do Distrito Estadual de Fernando de Noronha, um representante do Conselho Distrital de Fernando de Noronha, um representante da Secretaria de Ciência, Tecnologia e Meio Ambiente do Estado de Pernambuco, um representante do Destacamento de Aeronáutica de Fernando de Noronha do Segundo Comando Aéreo Regional, um representante da Associação Popular Noronhense, um representante do Centro Golfinho Rotador - Fernando de Noronha, um representante do WWF-Brasil, um representante da Fundação Pró-Tamar, três representantes das entidades representativas dos setores produtivos relacionados com as atividades de turismo ecológico em Fernando de Noronha. Sendo acrescido por meio da Portaria do Instituto Brasileiro do Meio Ambiente e dos Recursos Naturais Renováveis no 2, de 03 de janeiro de 2003, um representante da Sociedade Nordestina de Ecologia - SNE e um representante da Universidade Federal do Pernambuco - UFPE.

A Área de Proteção Ambiental de Fernando de Noronha tem contribuído para a manutenção da diversidade ecológica, estando presentes em seu território algumas das mais belas praias noronhense, além de espécies ameaçadas de extinção, mas que encontram ali um ambiente propício para seu desenvolvimento. 


\section{CONCLUSÕES}

A opção pela implantação de Unidades de Conservação de categorias diferentes em Fernando de Noronha trouxe equilíbrio na relação homem e natureza ali existente, já que ao mesmo tempo em que o Parque Nacional Marinho restringe o acesso humano e o uso direto dos recursos naturais do Arquipélago em determinadas áreas, colabora para a preservação do equilíbrio ecológico. A Área de Proteção Ambiental vai buscar a compatibilização da presença humana com a conservação da natureza, ajudando na Educação Ambiental por meio do contato direto com espécies diferentes de vida, propiciando uma experiência única de interação com a natureza da qual faz parte.

O êxito das Unidades de Conservação instaladas em Fernando de Noronha passa, no entanto, pela correta utilização das ferramentas de gestão disponíveis. Neste contexto, o plano de manejo, enquanto documento de regulamentação das ações desenvolvidas, e os Conselhos Deliberativos e Consultivos, por preverem a participação popular, irão se destacar.

Cabe, então, ressaltar que os Planos de Manejo, do Parque Nacional Marinho e da Área de Proteção Ambiental de Fernando de Noronha, já não estão suprindo as necessidades de regulação das atividades desenvolvidas no Arquipélago e encontram-se em processo de atualização, sob a coordenação do Instituto Chico Mendes de Biodiversidade, a fim de que possam se adequar as novas realidades enfrentadas, especialmente no que tange a ocupação humana, tanto de moradores quanto de visitantes.

No que se refere aos Conselhos: Deliberativo e Consultivo, verifica-se que estas ferramentas de gestão podem ser aprimoradas, pois existe uma participação institucional constante, por meio dos órgãos que por força de lei os compõem. Todavia, a participação popular direta mostra-se bastante discreta e resumida a temas pontuais e de interesse individuais latentes. A interação com os moradores da ilha precisa ser incentivada, uma vez que estes serão os principais atingidos pelas deliberações realizadas nas reuniões.

Portanto, o Parque Nacional Marinho e a Área de Preservação Ambiental têm desempenhado papel fundamental na conservação do meio ambiente em Fernando de Noronha, mas possuem o desafio constante de buscar caminhos que possam garantir concomitantemente a proteção dos ambientes naturais e a acomodação não impactante de moradores e visitantes.

\section{REFERÊNCIAS BIBLIOGRÁFICAS}

1. ANTUNES, P. B. Manual de Direito Ambiental: discussão de casos para cursos universitários com provas de concursos. 3 ed. Rio de Janeiro: Lumen Juris, 2011.

2. ANDRADE, L. M. S; GABRIEL, V. G; DIAS, M. B. Desafios para o futuro sustentável da llha de Fernando de Noronha: a visão ecossistêmica da ocupação humana. XIII Encontro da Associação Nacional de Pós-Graduação e Pesquisa em Planejamento Urbano e Regional. Florianópolis, 2009.

3. BATISTELLA, M. 1993. Cartografia Ecológica do Arquipélago de Fernando de Noronha, PE. Dissertação de Mestrado. USP. 
4. BECKER, B. K. Amazônia: geopolítica na virada do III milênio. Rio de Janeiro:Garamond, 2004.

5. BRASIL. Constituição da República Federativa do Brasil de 1988.

6. . Atos das Disposições Transitórias da Constituição Federal de 1988.

7. Decreto Federal n. 92.755, de 5 de junho de 1986. Declara Área de Proteção Ambiental o Território Federal de Fernando de Noronha, o Atol das Rocas e os Penedos de São Pedro e São Paulo, e dá outras providências.

8. Decreto Federal n. 96.693, de 14 de setembro de 1988. Cria o Parque Nacional Marinho de Fernando de Noronha e dá outras providências.

9. ___ Lei Federal n. 9.985, de 19 de julho de 2000. Regulamenta o art. 225, § 10, incisos I, II, III e VII da Constituição Federal, institui o Sistema Nacional de Unidades de Conservação da Natureza e dá outras providências.

10. Lei Federal n. 6.938, de 31 de agosto de 1981. Dispõe sobre a Política Nacional do Meio Ambiente, seus fins e mecanismos de formulação e aplicação, e dá outras providências.

11. Decreto-lei n. 4.012, de 9 de fevereiro de 1942. Cria o Território Federal de Fernando de Noronha.

12. Decreto n. 94.780 , de 14 de agosto de 1987. Dispõe sobre a estrutura básica de administração do Território Federal de Fernando de Noronha, e dá outras providências.

13. _. Instituto Brasileiro do Meio Ambiente e dos Recursos Naturais Renováveis- IBAMA. Portaria n. 190, de 31 de dezembro de 2001. Cria o Conselho Consultivo do Parque Nacional de Fernando de Noronha/PARNAMAR/FN, e dá outras providências.

14. __ Instituto Brasileiro do Meio Ambiente e dos Recursos Naturais Renováveis- IBAMA. Portaria n. 191, de 31 de dezembro de 2001. Cria o Conselho De liberativo da Área de Proteção Ambiental de Fernando de Noronha/PW

15. __ Instituto Brasileiro do Meio Ambiente e dos Recursos Naturais Renováveis- IBAMA. Portaria n. 2, de 03 de janeiro de 2003. Dispõe sobre alterações na Portaria/IBAMA no 191/2001, de 31 de dezembro de 2001.

16. NASCIMENTO, J. L; CAMPOS, I. B. Atlas da fauna brasileira ameaçada de extinção em unidades de conservação federais. Brasília: Instituto Chico Mendes de Conservação da Biodiversidade, 2011.

17. CARVALHO, E. F. Meio ambiente e Direitos Humanos. 2. ed. Curitiba: Juruá, 2011.

18. FIORILLO, C. A. P. Curso de Direito Ambiental Brasileiro. 5. ed. São Paulo: Saraiva, 2004.

19. GARBELINI, S. M. Manual Prático de Unidades de Conservação. Goiânia: Ministério Público do Estado de Goiás, 2011.

20. HASSLER, M. L. A. importância das Unidades de Conservação no Brasil: Sociedade e Natureza, n. 17, p. 79-89, 2005.

21. IBAMA/ FUNATURA - Instituto Brasileiro de Meio Ambiente e Recursos Naturais Renováveis e Fundação Pró-Natureza. Plano de Manejo do Parque Nacional Marinho de Fernando de Noronha. Brasília, 1990.

22. IBGE - Instituto Brasileiro de Geografia e Estatística. Censo Demográfico. Brasília, 2010. 
23. LEITE, J. R. M; AYALA, P. A. A interdisciplinaridade do Direito Ambiental e a sua equidade intergeracional. Sequência, v.21, n. 41, p. 113-116, 2000.

24. MACHADO, A. B. M; DRUMMOND, G. M; PAGLIA, A. P. Livro Vermelho da Fauna Brasileira Ameaçada de Extinção. Brasília: MMA, 2008.

25. MEDEIROS, R. Evolução das tipologias e categorias de áreas protegidas no Brasil. Ambiente e Sociedade, v. 9, n.1, p.41-64, 2006.

26. MENDONÇA E. S. A Reserva Particular do Patrimônio Natural (RPPN): o caso da Reserva Natural Menino Deus - Ilha de Santa Catarina. Florianópolis, 2004. Dissertação - Programa de PósGraduação em Engenharia de Produção da Universidade Federal de Santa Catarina. 2004.

27. MINISTÉRIO DO MEIO DO MEIO AMBIENTE/ARCADIS TETRAPLAN S.A. Plano de Manejo da APA Fernando de Noronha - Rocas - São Pedro e São Paulo. Brasília, 2004.

28. MINISTÉRIO DO MEIO DO MEIO AMBIENTE/INSTITUTO CHICO MENDES DE CONSERVAÇÃO E BIODIVERSIDADE/ELABORE. Estudo e Determinação da Capacidade de Suporte e Indicadores de Sustentabilidade do Arquipélago de Fernando de Noronha. Brasília, 2007.

29. MINISTÉRIO DO MEIO DO MEIO AMBIENTE/ SECRETARIA DE BIODIVERSIDADE E FLORESTAS. Sumário Executivo: Avaliação e ações prioritárias para a conservação da biodiversidade das Zonas Costeira e Marinha. Brasília, 2002.

30. MILARÉ, E. Direito do Ambiente. 5. ed. São Paulo: Revista dos Tribunais, 2007.

31. MORAIS, C. K.T; LIMA, S. A; ALMEIDA, G. E. M. Meio Ambiente ecologicamente equilibrado: Direito ambiental, fundamental e humano, dever social: Qualitas Revista Eletrônica, v. 11, n. 1, p. 1-15, 2011.

32. OLIVEIRA, S. M. B; PESSENDA, L. C. R; BABINSKY, L; GIOIA, S. M. C. L; FAVARO, D. I. T. Solos desenvolvidos sobre diferentes rochas vulcânicas da llha de Fernando de Noronha: padrão de elementos terras raras e composição isotópica do chumbo: Revista do Instituto de GeociênciasUSP, v. 11, n. 3, p. 97-105, 2011.

33. PÁDUA, M. T. J. Do Sistema Nacional de Unidades de Conservação. In: MEDEIROS, R; ARAÚJO, F. F. S. Dez anos do Sistema Nacional de Unidades de Conservação da Natureza: lições do passado, realizações do presente e perspectivas para o futuro. Brasília: Ministério do Meio Ambiente, 2011.

34. PEIXOTO, M. F. C. C; LIMA, J. R; SANTOS, A. M.S; CALEGARI, L. Percepção no Ambiente Acadêmico sobre sustentabilidade ambiental e o uso do papel: Caminhos da Geografia, v. 14, n. 47, p. 74-84, 2013.

35. RYLANDS, A.B; BRANDON, K. Unidades de Conservação Brasileira. Megadiversidade, v.1, n. 1, p. 27-35, 2005.

36. SCHENINI, P. C; COSTA, A. M; CASARIN, V. W. Unidades de conservação : aspectos históricos e sua evolução. Congresso Brasileiro de Cadastro Técnico Multifinalitário, Florianópolis, 2004.

37. SILVA, M. B. L. Fernando de Noronha: cinco séculos de história. Recife: Editora Universitária da UFPE, 2013.

38. SILVA, J. A. Direito Ambiental Constitucional. 4. ed. São Paulo: Malheiros, 2003.

39. SIRVINSKAS, L. P. Manual de Direito Ambiental. 2. ed. São Paulo: Saraiva, 2003. 
40. TADA, C. K; GRANVILLE, M; MATHES, Z; GROSSMAN, A. Fernando de Noronha: $3^{\circ} 50^{\prime} \mathrm{S} 32^{\circ} 24^{\prime} \mathrm{W}$. São Paulo: Bei, 2010

41. TEIXEIRA, W; CORDANI, U. G; TEIXEIRA, M. G; MENOR, E. A; LINSKER, R. Arquipélago de Fernando de Noronha: o paraíso do vulcão. São Paulo: Terra Virgem, 2003.

42. TRAVASSOS, P. L'étudedesrelationsthons-environnementdansl'océanAtlantique intertropical ouest: cas de l'albacore (Thunnusalbacares, Bonnaterre 1788), dugermon (Thunnusalalunga, Bonnaterre 1788) et duthonobèse (Thunnusobesus, Lowe 1839).Tese de Doutorado. I'UNIVERSITE PARIS, 1999. 